\title{
An Integrated BIM System to Track the Time and Cost of Construction Projects: A Case Study
}

\author{
Ahmad Jrade and Julien Lessard \\ University of Ottawa, 161 Louis Pasteur Private, Ottawa, ON, Canada K1N 6N5 \\ Correspondence should be addressed to Ahmad Jrade; ajrade@uottawa.ca \\ Received 25 June 2015; Revised 28 September 2015; Accepted 27 October 2015 \\ Academic Editor: Eul-Bum Lee
}

Copyright ( 2015 A. Jrade and J. Lessard. This is an open access article distributed under the Creative Commons Attribution License, which permits unrestricted use, distribution, and reproduction in any medium, provided the original work is properly cited.

\begin{abstract}
Many construction projects suffer from poor design and from inconsistent time and cost management. This situation has led to rethinking of the industry's performance and how it could be improved. Technology is breaking through design and management practices. Earned value management (EVM) enables better management of time and cost constraints. Building Information Modeling (BIM) is recognized to improve the planning and realization of a construction project. The present paper proposes an integrated time and cost management system (ITCMS), where an EVM platform is used in a virtual environment during the planning and construction phases of a project. The ITCMS enables early involvement and project integration plus thorough time and cost management. The system consists of four modules and 13 different processes. The ITCMS is beneficial at the design stage; construction professionals are able to synchronize the building model with time and cost parameters as well as optimize it through a clash detection process that results in budget and schedule compressions early on. The ITCMS is a useful tool for construction and engineering managers that strive to increase projects' performance. The authors demonstrate in this paper the validity of using the ITCMS through an actual project.
\end{abstract}

\section{Introduction}

Multiple issues such as decrease in labor productivity, poor identification of design requirements, and lack of steady and professional construction management hinder the construction industry. This situation made the industry reevaluate its performance and look into ways for improvement. Project integration is essential for success; designers and constructors must collaborate and communicate effectively to keep budgets and schedules on the right track. Technology is slowly breaking through construction management practices and new contractual methods are emerging. BIM improves technical work at the design stage by creating 3D models that integrate all building's features and it better represents the infrastructure's requirements. Those models can also be enhanced if linked with schedule (4D) and costs (5D); the construction can thus be better planned almost entirely at the design phase. Time and cost controls are very important for any construction organization. EVM is widely used for monitoring and controlling time and cost parameters according to a baseline and rendering forecasts.

Budget and schedule overruns in a big number of construction projects have set grounds for the present research. Firstly, the authors aim at providing an exhaustive background on the principal difficulties within the construction management industry and looking for ways for improvement, noticeably through the use of technology. Secondly, the authors propose a methodology for the development of a system that will improve time and cost management of construction projects, within a virtual design and construction working environment. Finally, the proposed solution will be tested in a real-case project. It is believed that construction and engineering managers as well as project stakeholders will benefit from this system.

\section{Literature Review}

Glavinich [1] believed that constructability refers to the ease with which the raw materials of the construction 
process can be brought together by a builder to complete the project in a timely and economic manner. Tatum [2] denotes constructability as the integration of the design and construction. Johansen and Wilson [3] questioned the necessity of intense construction planning in the design phase; they reached a conclusion that there is reluctance within the industry to accept first planning initiatives. Their major finding is that there is a lack of convergence between the design and construction team planning ideas, thus preventing achievement of project success. Mismanagement, as per Chester and Hendrickson [4], originates from the drive to build cheaper and faster, designers performing a less thorough job and managers not planning as well as they should. Glavinich [1] suggested that a design-phase scheduling and a check of drawings and specifications be performed before the construction would lead to less budget and schedule impact to the owner. With construction projects' performance being evaluated mostly along budget and schedule considerations, it is imperative that time and cost control needs to be a major focus of the construction manager. An early involvement and proactive presence of a construction professional is needed during the development of the project plan to ensure that construction plan and schedule are sound. In the same direction, Miyagawa [5] developed an automated and computerized system intended to control the manageability of the construction planning. The outcomes of this system are interesting and include noticeably the ability to integrate the project design with project planning, scheduling, and diagnosis techniques. The user can then simulate the construction process. Stevens [6] presented the integrated cost/schedule performance curve that achieves cost and schedule control against project plan. Used as a visualization summary tool, it can also be used as a model for predictions and forecasts. Perera and Imriyas [7] proposed the combined usage of MS Access (database) and MS Project (scheduling) software as a project time and cost control system. Olawale and Sun [8] suggested five mitigating measures groups to improve project time and cost control, which are design changes, risks and uncertainties, inaccurate evaluation of project durations, complexity of works, and nonperformance on subcontractors.

Fleming and Koppelman [9] considered that EVM is not adopted widely on private projects. Therefore, Czarnigowska [10] looked at practical problems of the application of EVM in construction. The author found that obtaining true values for tasks' completion rate can be difficult and needs to be developed along guidelines rather than actual measurements. Cost data can be difficult to gather for the EVM model; such difficulties can thus alter the schedule variance and index. Czarnigowska [10] recommended the use of the Earned Schedule method rather than the EVM with little manipulation in the calculations; this method allows construction managers to perform comprehensive analyses to ease project monitoring and status rather than forecasts, which are not likely to be accurate. In light of such problems with the effective utilization of EVM in the construction industry, some scholars suggested methods to successfully convey the benefits of EVM in project control. Ghanem et al. [11] proposed a method where materials would be tracked with a Radio Frequency Identification (RFID) tag to be then scanned on construction sites and imported in a database that would be used to determine the percentage complete of tasks and perform EVM. Multiple changes on a construction project can complicate the EVM control process [12]. Kim [13] looked at the application of EVM on residential projects and the proper understanding of schedule and cost performance indices. The author introduced a judgmental approach for analyzing schedule and cost performance. Furthermore, the integration of IT systems is particularly important in project control and monitoring. Chou et al. [14] believed that project information must be presented visually and automatically for efficient control process. Turkan et al. [15] proposed a system where actual construction progress is scanned with a $3 \mathrm{D}$ object laser recognition technology. The rendered scan was then linked to the actual BIM design model and EVM calculations could be performed. The above referred to time, cost, and EVM control systems are proven to be resourceful for managing construction projects. However, the latter are mostly being used during the execution phase. The construction industry practitioners would benefit from early involvement and real-time integration and visualization for budget and schedule control.

BIM is being increasingly present in the mind of construction practitioners. Eastman [16] presented BIM as a more integrated design and construction process that results in better quality buildings at lower cost and reduced project duration. The following simple definition was proposed: BIM is an enabler of constructability. Abourizk [17] approached the role of simulation in construction projects. He showed that models were used to develop better project plans and to improve overall construction management. An integrative solution, enabling quick generation of project schedule, costs with relation to design would achieve a high automation level of construction modeling and simulation. Barlish and Sullivan [18] found that significant savings are obtained through BIM with reduced requests for information (RFI) and change orders, leading to improved return on investment (ROI) and profit. On the other hand, Staub-French and Khanzode [19] realized that the adoption of a 4D process enables the linkage of a schedule to 3D elements and results in construction animation. According to Staub-French and Khanzode [19], multiple benefits are brought in a project with $3 \mathrm{D}$ and $4 \mathrm{D}$ processes, listed are some of which: identification of design conflicts at the design phase, improvement of productivity, fewer change orders, better cost control, better communication of scheduling intent, and identification of project status at any time during the project. As per Arain and Burkle [20], 3D models help in identifying potential technical and management issues with the project at an early stage. Visualization enables the representation, communication, and coordination of visual project information among project participants [21]. Visualization also allows the identification of conflicts at the design phase through clash detection [19]. Clash detection changes must then be integrated with the budget and schedule aspects of the project; it is an iterative process until the final design is approved.

Feng et al. [22] studied the application of a time-cost integrated schedule for construction project within BIM constraints, 
(1) Convenient, efficient, and easy to learn and manage.

(2) Improved project coordination and communication must be inherent to the system and all efforts towards project budget and schedule success.

(3) The system should integrate every construction practitioner's work in a sole process/tool.

(4) Project's information must always be available and understandable.

(5) Built for future improvement and allowing flexibility.

Box 1: Proposed integrated time-cost management system's requirements.

(1) Agreement and use of a sole construction specifications standard and WBS by the project's designers (architects, engineers) and the construction manager or prime contractor.

(2) The building model must be constructed exactly in line with the WBS.

(3) Integration of different software; most of the linkages of software should be automated whenever possible.

(4) Ability to associate time and cost values with each of the model's components, those being modifiable quickly and easily through automation.

(5) Visualization is used as a tool for communicating with project stakeholders and to assess constructability.

(6) Project's time and cost parameters can be set as a baseline (with EVM method) before the construction starts.

(7) Budget and schedule are both linked within a sole platform.

(8) Changes to the project can be implemented at any time during the design or construction process.

(9) System's iterations must be feasible readily.

(10) Ability to generate performance reports and ratios based on the EVM method at any point during the project and visually assess project success.

Box 2: Specifications of the proposed integrated time-cost management systems.

to which they refer as a visualized time-control model. The addition of a cost component in such a model enables a fifth dimension (5D). The authors deduct from above that BIM alone will not suffice in improving construction projects; involvement of a construction practitioner at an early stage and project integration among stakeholders will ensure that the project's budget and schedule objectives are preserved before the construction starts. Moreover, the systems mentioned above are mostly being used during the design stage, for preparing construction models. Construction projects would be improved with BIM models being also used during the construction phase. To successfully implement tools and processes within BIM constraints in a construction project, a new contractual method has been developed that is referred to as Integrated Project Delivery (IPD). Kent and Becerik-Gerber [23] found that IPD would generally be preferred to traditional contracting method by construction practitioners. The coming of IPD demonstrates that the construction industry seeks new contractual practices that set aside business moneymaking and foster project integration and collaboration for better schedule and budget results.

The literature review has shown that BIM is an enabler of constructability. Furthermore, it was found that EVM is a useful tool that enables proper monitoring and controlling of time and cost relative to the project's scope. EVM also allows construction managers to compare their project's progress to the planned baseline and then assess whether their construction will meet budget and schedule goals. Multiple time and cost tracking systems for construction exist. However, the authors have not been able to find a system that has characteristics and multiple tasking ability similar to the ITCMS. Unlike the research reviewed in this section, the ITCMS is used during both the planning and execution phase of any project. It is believed that the ITCMS, coupled with BIM tools and processes and used in a virtual design and construction environment, will better promote construction practices and improve budget and schedule success on most of future construction projects. The integration between ITCMS and BIM will help construction managers take vital decisions during early design stage of the project with an in-depth time and cost planning; every item of the 5D model is directly linked to the schedule and budget. Moreover, synchronized EVM during the construction phase, along with timely updates of the model, fosters sound project management practices, which will potentially improve its progress and success within time and cost constraints.

\section{Methodology and System Development}

The requirements and specifications of the proposed system are established based on an intense literature review and accordingly the system architecture is developed. Afterwards, a project management and process-oriented methodology is carried out as part of the conceptual workflow, involving the following three important phases: (1) planning, (2) executing, and (3) monitoring and controlling. Box 1 lists the user's requirements for an ITCMS used in a virtual design and construction environment; the general intent of the study is to develop a system that will be efficient to use, ease construction managers' task when planning and monitoring time and cost parameters within a project, and enhance project coordination and communication among stakeholders. Box 2 exhibits 


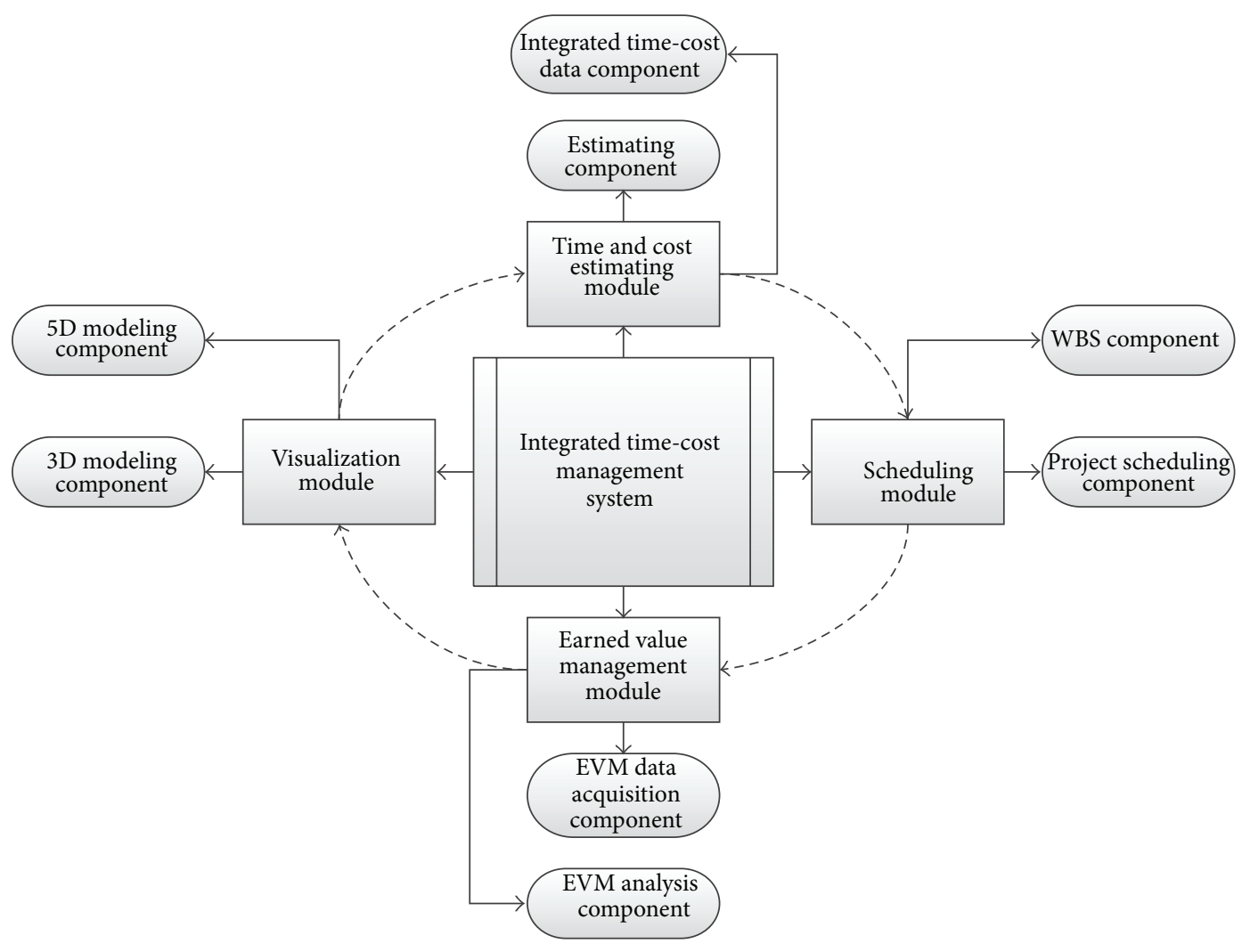

FIGURE 1: Integrated time-cost management system modules and components.

the specifications taken into consideration while developing the proposed system. These specifications are applied with the willingness to ensure integration and synchronization throughout computer management tools, such as scope of work, schedule, budget, EVM platform, and building model.

The proposed ITCMS will ensure a good flow of information and will foster good collaboration within the project team. Furthermore, the technical work associated with this proposed system needs to be well integrated to limit rework and incomprehensiveness where automation is a key to success. The resulting work will allow the design team to construct a sound building model with high level of constructability and the construction manager to assess project's performance in terms of budget and schedule progress at any point of time of the project. The proposed system includes four different modules that are interrelated to each other and continually interact within the inherent system's iteration processes. Figure 1 illustrates the system's interconnected modules and their associated components. These modules are (1) visualization module, (2) time and cost estimate module, (3) scheduling module, and (4) earned value management (EVM) module. The visualization module includes the actual building model that allows $3 \mathrm{D}$ and $5 \mathrm{D}$ visualization. From this module, it is possible to derive time and cost values for each component of the modeled building. Then, by linking this data to each of the construction tasks, the user can develop the schedule and the EVM modules, respectively. Figure 1 illustrates the system's interconnected modules and their associated components, while Figure 2 presents the architecture of the proposed system in which clear description of the required inputs, analysis, criteria, and outputs for both the design and construction phases is provided.

It is worth mentioning that both design and construction phases have their own set of inputs and outputs. The principal inputs of the system are an integrated WBS and a 3D building model that are provided initially by the design team. Then, the construction team works with the design team to improve the model by evaluating time and cost parameters and assessing constructability with clash detection and by doing general visualization and evaluation of the model. Iterations of the project's budget and schedule are created throughout this phase. When the building model is finished, the generated outputs of the design phase include final quantity takeoffs, budget and schedule, the EVM platform with time-cost baselines, and a 5D model that integrates time and cost values for the building and its associated components. At the construction phase, the EVM module is used to establish project performance based on the percentage of physical work put in place. Change management is also performed, followed with an updated budget, schedule, and 5D model of the building. Once the system's modules and its architecture are established, the development will commence by assessing the conceptual workflow as shown in Figure 3.

The system's workflow begins at the design phase where the $3 \mathrm{D}$ building model is developed in line with a WBS that is agreed by the project team. The WBS has to be 


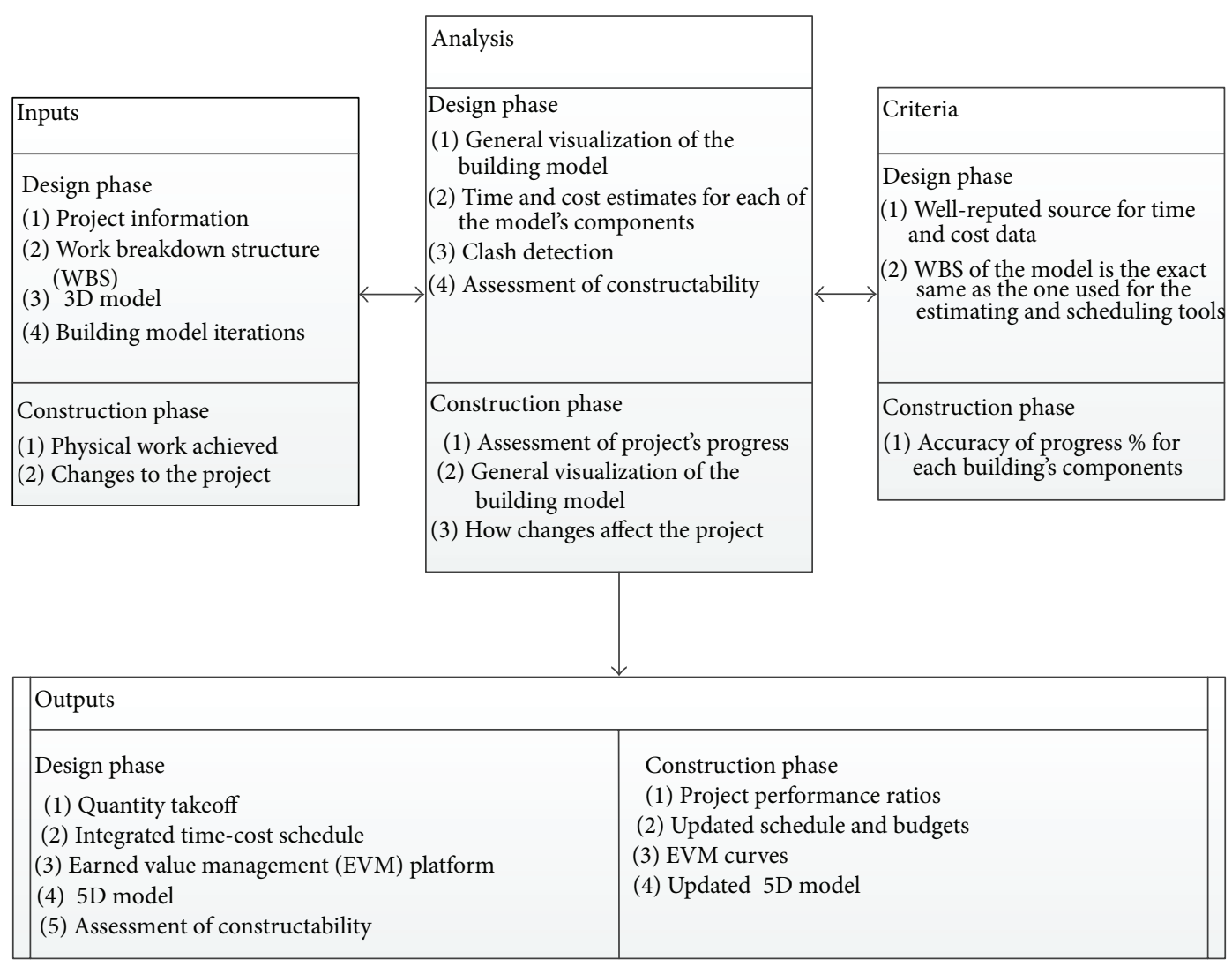

FIGURE 2: Integrated time-cost management system architecture.

developed using recognized database such as Uniformat or Masterformat, in order to ensure synchronization between the building model and the time-cost control system (define WBS and build 3D model in Figure 3). The construction team holds the responsibility to perform quantity takeoffs, time and cost estimates, and a work schedule that will be iterated to ensure the project constructability. The latter outputs are performed using a software (Autodesk Quantity Takeoff() that scans the building model and generate automated detailed cost and time estimates, using data that has previously been set in the software (perform quantity takeoff and estimate time and cost in Figure 3). Time and cost data has to relate exactly to each of the building components (WBS items). Using the time and cost data, the project schedule can be built using the same WBS framework, with software such as Microsoft Project $($; costs are also incorporated in the software, for the EVM platform that will later be constructed (define project schedule in Figure 3). A 5D model will also be created by the construction team by incorporating the costs and schedule in Autodesk Navisworks $@$ software, the model being then used as a visualization and clash detection tool to iterate the building model during the planning phase until project's objectives are met. The project team will evaluate the building model in accordance with the budget and schedule parameters and iterate until final acceptance is achieved by all the parties (use model as a visualization tool, perform clash detection, and establish 5D building in Figure 3). At this point, the EVM platform will be built and the time and cost baselines will be set before the construction begins. The EVM platform is constructed with MS Project $\odot$ and Excel@, using cost data that is collected in the schedule by first setting the baseline and then measuring the planned value (or costs) at periodic dates of the schedule (build EVM platform and set time and cost baseline in Figure 3). The process at the planning phase is iterative; users are encouraged to go back and improve the $5 \mathrm{D}$ model until it is considered final and ready for the construction phase. At this point, the project team can approve the 5D model and begin execution (approve final design, integrate and construction starts processes in Figure 3). The developed EVM platform will then be used during construction as an executing, monitoring, and controlling tool. By assessing the project's progress as a percentage (\%) of each component of the updated building model (i.e., on a monthly-basis), users will be able to first update the schedule and then report the data in the EVM platform to evaluate the overall project performance (manage building model, perform changes, assess timely project progress, update work schedule, update project costs, and update EVM platform in Figure 3). EVM curves and ratios would then be generated automatically to provide updated information to the construction manager on the project's health, for immediate action in case of budget or schedule problematics (generate EVM curves and ratios/assess project performance in Figure 3). In the meantime, design and other changes brought during construction can be integrated to the building model and extended to 


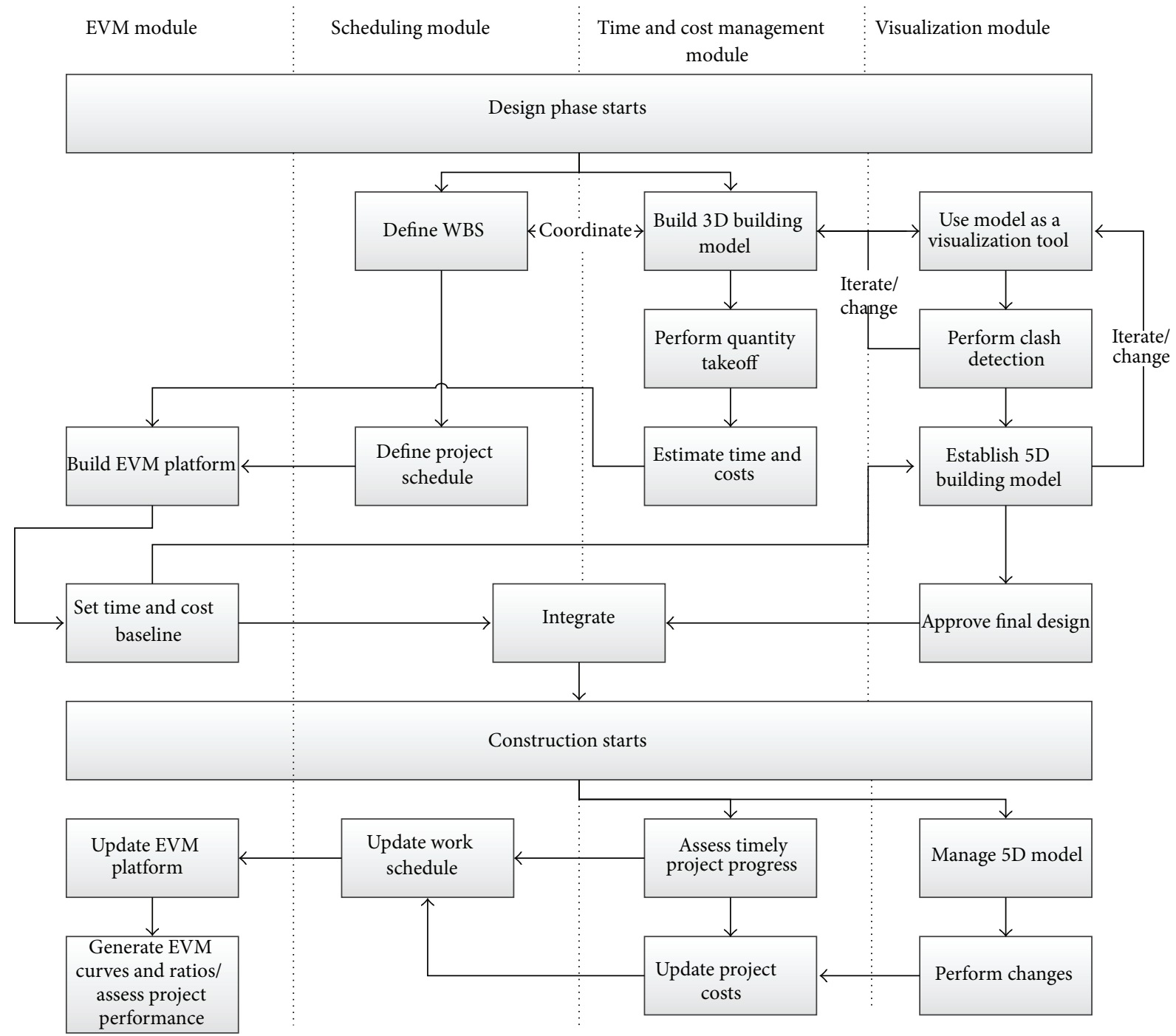

FIgURE 3: Integrated time-cost management system workflow.

the EVM platform in the same way as in the design phase (perform changes in Figure 3). The 5D model will also be used during the construction as a visualization, communication, and coordination tool for every project's stakeholders. The ITCMS workflow during the planning phase involves many processes that are linked to each other and can be iterated. During the execution phase, the processes are fully integrated and resemble a periodic check of the project's health in accordance with budget and schedule baselines, using the EVM platform.

\section{System Validation}

In this section, the developed system will be validated to test its workability and potentials. The system validity and its outcomes will be tested with two scenarios that occur either during the design or during the construction phase. Design iteration will be demonstrated and then the project will be updated during the construction phase. An actual project is selected to do the validation. The project is a new car dealership of approximately 40,000 square feet. The new building is located in Gatineau, Québec, Canada. The project information has been provided by Beaudoin, a construction management firm that acts as the prime contractor for this project. The project has been developed from a preliminary design perspective using the developed system. BIM's tool used in developing the building model is Autodesk Revit 2013 $\odot$ because it allows for the integration of architectural, structural, mechanical, electrical, and other models into a sole 3D model, which simplifies the coordination among the design team and eases the transition to the planning work and the construction phase. Afterwards, the model is exported into Autodesk Quantity Takeoff $\odot$ to perform the time and cost estimates as seen in Figure 4.

The system estimated the project costs as $\$ 2,287,971.83$, which is obtained from exporting the Quantity Takeoff and then integrating it with the durations in a Microsoft Excel@ sheet. These costs do not include the general conditions and 


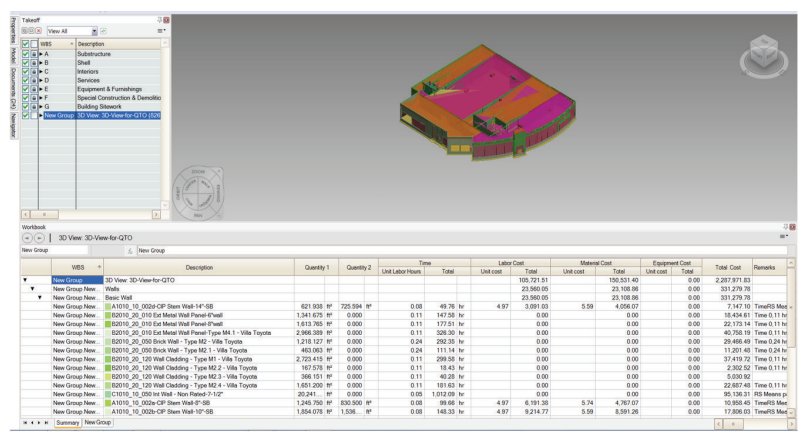

FIGURE 4: Autodesk QTO time and cost takeoff and estimates.

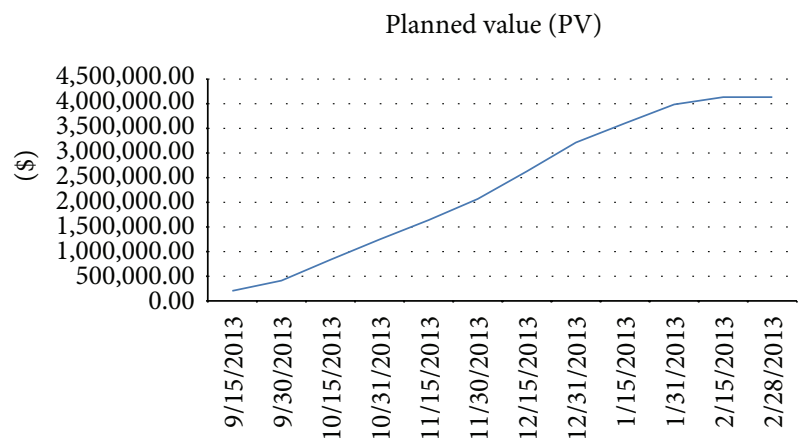

FIGURE 5: PV curve.

management costs that will be obtained when developing the project schedule in the next section. The aggregated hours required to perform the work are found to be 11,731 hours. The time and cost estimates are calculated based on RS Means 2013. Some of the costs and time data have been attributed randomly as well as the crews and the length of the working shifts. This demonstrates the need for external construction expertise such as the specialized contractor or construction manager during the design phase.

Using the WBS and the time and cost estimates, the schedule is constructed. The project construction duration is calculated to be 121.75 days. Once the general conditions and management costs are added, which are established randomly at $\$ 2,500.00 /$ day, the total project cost is estimated to be $\$ 2,592,346.56$.

The cost obtained during the estimating process for every work item is attached to each activity of the project schedule. Toward the end, the planned values (PV) for each of the project status dates that have been established are acquired. For this dealership project, it has been determined that, every two weeks, a measurement on the 15th and the last date of each month would be sufficient to perform accurate earned value management.

By retrieving the PV numbers from the project schedule, the EVM platform can then be developed in Microsoft Excel and the PV curve is drawn as shown in Figure 5. The PV curve shows the monetary level of accomplishment (vertical axis, $\$$ value) the project should attain according to the as planned values at any point of time (horizontal axis, dates).
To develop the 5D model, it is necessary to import the 3D model and the project schedule into Autodesk Navisworks $\odot$. With the use of the selected WBS, each of the model elements has been associated with an activity in the schedule. Then, the construction animation can be performed.

Clash detection management is also a feature of the ITCMS. Figure 6(a) represents the clash detection performed by the model. Since the model is applied at the conceptual design stage, many clashes were found where the number reached 976 clashes as shown in the figure. Figure 6(b) illustrates a demonstration of the ITCMS iteration function that is performed on only one of these clashes, which is a cross bracing bar located right through an exterior door. On the lower part of Figure 6(b), it can be seen that the steel members have simply been removed.

Now that the model has been revised, a new time and cost estimation is performed in Autodesk Quantity Takeoff. Figure 7(a) illustrates the values of the time and cost estimate before fixing the clash and Figure 7(b) shows the values after it has been fixed. The model originally contained 826 elements but after doing the changes it contained 824 ( 2 steel members removed, in grey in Figure 7(b)). Moreover, the total project cost has changed from $\$ 2,287,971.83$ to $\$ 2,287,073.73$ and the time changed from 5,632 to 5,372 hours.

Once the quantity takeoff and estimates are completed in Autodesk Quantity Takeoff, the Excel file can be exported from the previous software and then the time-cost integrated sheet is updated. Since the two files are linked to each other, this process is automatically performed. Indeed, a detailed verification of the work by the design and construction team is strongly encouraged. Next, the schedule is updated. Since the schedule generated by MS Project $\odot$ is also linked with the integrated time-cost spreadsheet, then this process is thus automated.

Therefore, the project duration dropped from 121.75 days to 121.67 days due to the reduction in the steel framing work. Reiterating that the total project cost is linked to the activity "general conditions and management" in MS Project, we can now retrieve the updated total project cost from MS Project. It is obvious that the costs came down from $\$ 2,592,346.88$ to $\$ 2,591,212.80$. It is worth noting that the model was applied during the conceptual design stage of the case project; therefore, an approximated calculation of the time and cost saving resulting from identifying the whole 976 clashes would be 6 days and \$115,000, respectively. However, these values would change as the design would reach its final stage. Next, the EVM platform is modified with the planned value (PV) calculations generated in MS Project. This will thus lead to revised EVM curves.

Finally, the revised schedule is updated in Navisworks. This iteration process will occur several times during the design phase until the team reaches a satisfactory complete integrated model that has taken constructability into account, which will lead to a facilitated and productive construction phase. During construction, the ITCMS requires timely updates to ensure that the project is progressing as planned in the design phase. To do so, scheduling techniques and EVM are used to report performance, and the $5 \mathrm{D}$ model is communicated to the project's stakeholders to ensure proper 


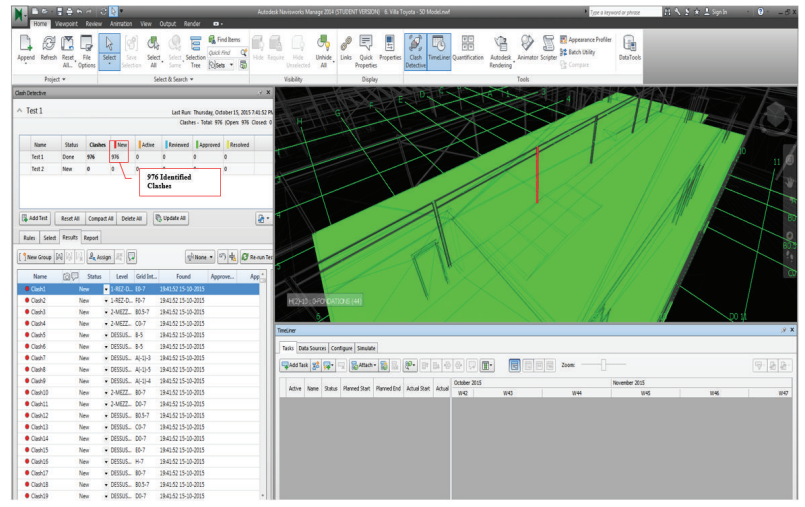

(a)

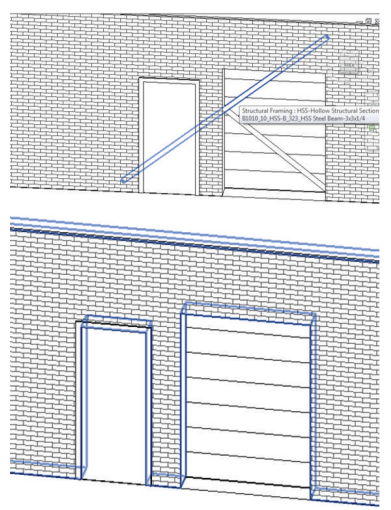

(b)

Figure 6: (a) Clashes detected by the model. (b) One of the detected clashes, interference between a door and a steel member.

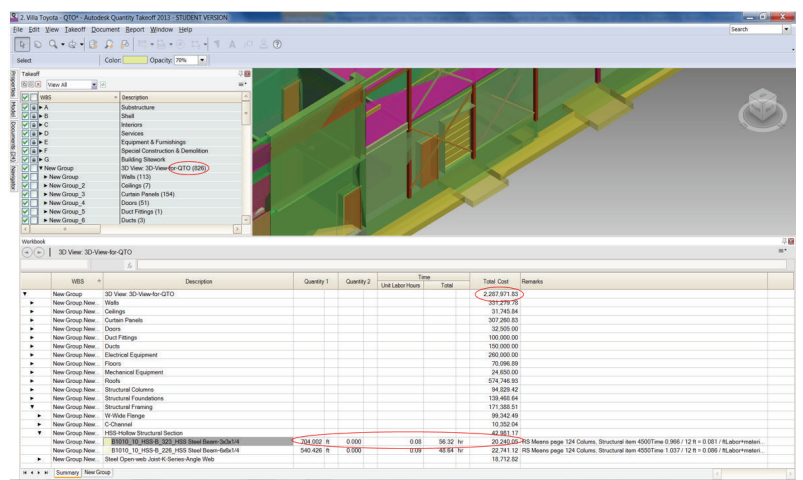

(a)

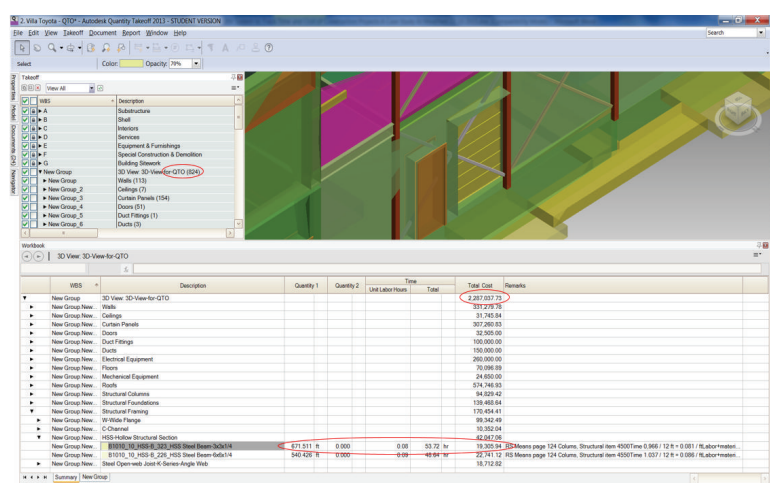

(b)

FIGURE 7: (a) Autodesk QTO before modifying the time and cost estimates. (b) Autodesk QTO after modifying the time and cost estimates.

coordination of the work and thorough understanding of the project objectives. An update of the schedule including time delays due to poor weather and lengthy activities is presented, with progress reporting using the previously established EVM platform and an update of the 5D model. An arbitrary update of the schedule is first performed. The progress status date is set on December 15, 2013, in MS Project. Tasks durations are modified-diverging somehow from the baseline-with the hypothesis that some unforeseen conditions were discovered during construction and that bad weather during winter happened and delayed some construction activities. The updated schedule is presented in Figure 8 . The project duration has slipped by almost 4 days at this point of time.

Now, the user is able to retrieve the PV from MS Project and monitor the project performance. Looking at the EVM curves in Figure 9(a), the user can visually assess that the project is behind the expected progress. The EV (red) and the AC (green) curves are, in this case, almost the same. These curves are showing the earned value (EV), according to the initial planning, and the actual costs (AC). Figure 9(b) exhibits the variation of the Schedule Performance Index (SPI-blue) and the Cost Performance Index

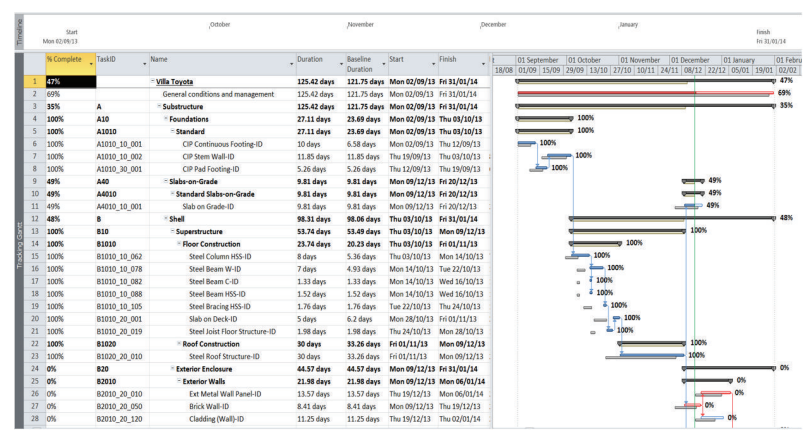

FIGURE 8: Schedule updated during construction.

(CPI-red) throughout the project. The SPI curve shows that the performance of the schedule is not constant. Therefore, the schedule is definitely an issue that the construction manager should look at.

The next step would be to synchronize the new project schedule in Navisworks. The updated schedule in the $5 \mathrm{D}$ model is reflected with a new ending date on January 31, 2013, instead of January 28, 2013, as initially planned. 


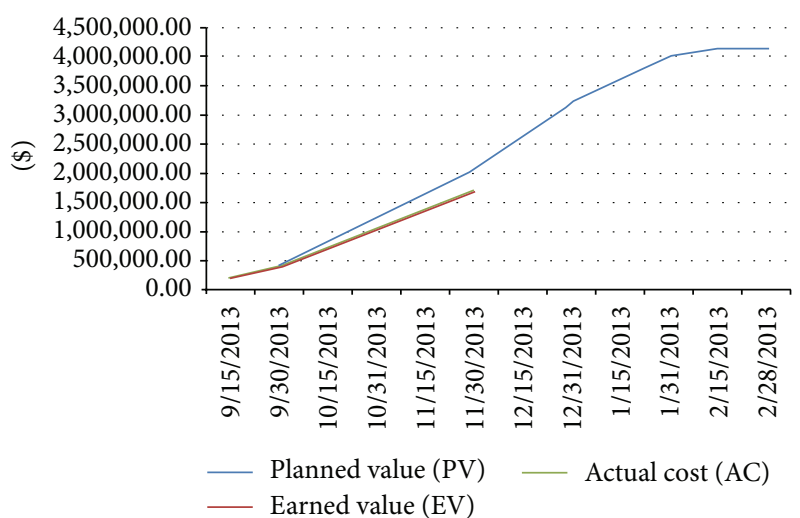

(a)

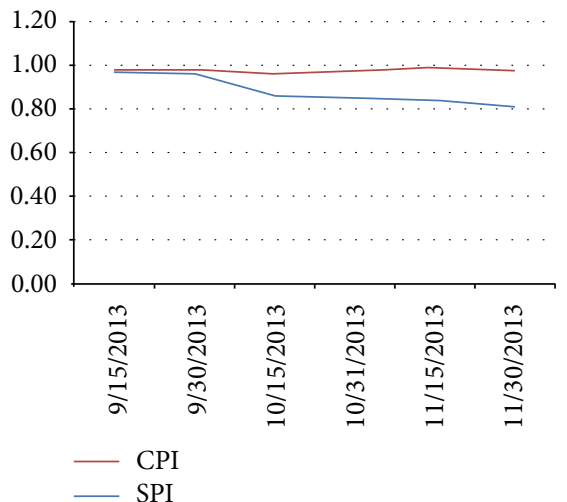

(b)

FIgUre 9: Updated EVM curves.

To conclude, it was demonstrated that the proposed ITCMS is performing as expected and meets the requirements and specifications set beforehand. At the design phase, model iterations are performed and every output needs to be updated; even though the system has some automated features, computer maneuvers are still necessary for some of the process in the design phase. The same thing happens during the construction phase. Updates to the schedule and 5D model are readily feasible and valuable for assessing the project's performance with the EVM indicators. The ITCMS has an incredible number of possibilities in terms of computer operations and data analysis. It is undeniable that, with a complete design and construction project, having the ability to ensure coordination and integration among the project team with BIM tools and processes, paired with the use of an EVM platform that enables a continual review of the performance, would be useful. Moving forward, there are several improvements and additions that could be brought to such a system in order to get the best of the practice in the construction management practice field.

\section{Discussion and Conclusion}

In an effort to merge a time and cost management system with future construction best practices, the study objective was to develop an integrated time-cost management system (ITCMS) and to test it on a real-case scenario. The conceptual methodology revealed that this system would consist of four modules: time and cost estimating, scheduling, visualization, and EVM. A conceptual workflow was also presented and several tasks to be performed at the design and construction phases developed. The system can be described as a convenient tool that takes advantage of improved team coordination and visualization tools to associate detailed time and cost values with each component of a 5D building model. The system then ensures budget and schedule monitoring throughout the project, with the aid of an earned value management platform. The ITCMS was implemented with thirteen detailed processes to be performed at the design and construction phases. Most of the work is to be performed with computer tools; pieces of software such as MS Project,
Microsoft Excel, and Autodesk's Revit, Quantity Takeoff, and Navisworks were used. The ITCMS has the potential to improve the actual construction practices. Multiple benefits are identified from applying it to the actual project such as ability to associate detailed time and cost values to each of the building model components during the design phase; facilitated estimating process with automated outputs; creation of a time and cost baseline that serves as a reference for EVM performance reporting at any time during the construction; visual tool fostering better comprehension among the project team, particularly with people that have less technical or management knowledge. It is believed that the ITCMS is beneficial to construction managers; the functionality and dependency of the developed model have been proven by using an actual case project. Its budget and schedule management platform, coupled with BIM tools and processes, will inevitably improve construction productivity, constructability, and overall performance if applied rigorously. Taking its roots in early involvement and project integration, the ITCMS enables collaboration and sharing of construction expertise at the benefit of all the stakeholders, working towards a common goal which is budget and schedule performance, a virtue that the industry professionals are now seeking. Virtual design and construction already have breakthrough; engineering and construction managers must promote its benefits and drive its integration in the industry's practices. This is an ongoing research; authors are working on adding other project management parameters such as risk and quality that could be introduced in the system and would highly benefit construction managers in effectively managing their projects. Furthermore, authors are working on incorporating a sixth dimension to ITCMS, which is facility management. This would be an extended enhancement of the present system by integrating life-cycle costs in a $6 \mathrm{D}$ building model, which is considered to be a promising advancement for the construction industry.

\section{Conflict of Interests}

The authors declare that there is no conflict of interests regarding the publication of this paper. 


\section{References}

[1] T. E. Glavinich, "Improving constructability during design phase," Journal of Architectural Engineering, vol. 1, no. 2, pp. 7376, 1995.

[2] C. B. Tatum, "Improving constructibility during conceptual planning," Journal of Construction Engineering and Management, vol. 113, no. 2, pp. 191-207, 1987.

[3] E. Johansen and B. Wilson, "Investigating first planning in construction," Construction Management and Economics, vol. 24, no. 12, pp. 1305-1314, 2006.

[4] M. Chester and C. Hendrickson, "Cost impacts, scheduling impacts, and the claims process during construction," Journal of Construction Engineering and Management, vol. 131, no. 1, pp. 102-107, 2005.

[5] T. Miyagawa, "Construction manageability planning—a system for manageability analysis in construction planning," Automation in Construction, vol. 6, no. 3, pp. 175-191, 1997.

[6] W. M. Stevens, "Cost control: integrated cost/schedule performance," Journal of Management in Engineering, vol. 2, no. 3, pp. 157-164, 1986.

[7] A. A. D. A. J. Perera and K. Imriyas, "An integrated construction project cost information system using MS AccessTM and MS ProjectTM," Construction Management and Economics, vol. 22, no. 2, pp. 203-211, 2004.

[8] Y. A. Olawale and M. Sun, "Cost and time control of construction projects: inhibiting factors and mitigating measures in practice," Construction Management and Economics, vol. 28, no. 5, pp. 509-526, 2010.

[9] Q. W. Fleming and J. M. Koppelman, "Earned value project management," Cost Engineering, vol. 39, no. 2, pp. 13-15, 1997.

[10] A. Czarnigowska, "Earned value method as a tool for project control," Budownictwo i Architektura, vol. 3, pp. 15-32, 2008.

[11] A. G. Ghanem, A. G. Ghanem, and Y. A. Abdelrazig, "A framework for real-time construction project progress tracking. Earth and Space," in Earth and Space 2006-10th Biennial International Conference on Engineering, Construction, and Operations in Challenging Environments, March 5, 2006-March 8, 2006, League City/Houston, TX, United States, pp. 1-8, American Society of Civil Engineers, 2006.

[12] J.-S. Chou, "Cost simulation in an item-based project involving construction engineering and management," International Journal of Project Management, vol. 29, no. 6, pp. 706-717, 2011.

[13] S.-C. Kim, "Project success indicators focusing on residential projects: are schedule performance index and cost performance index accurate measures in earned value?" Canadian Journal of Civil Engineering, vol. 36, no. 11, pp. 1700-1710, 2009.

[14] J.-S. Chou, H.-M. Chen, C.-C. Hou, and C.-W. Lin, "Visualized EVM system for assessing project performance," Automation in Construction, vol. 19, no. 5, pp. 596-607, 2010.

[15] Y. Turkan, F. Bosché, C. T. Haas, and R. Haas, "Toward automated earned value tracking using 3D imaging tools," Journal of Construction Engineering and Management, vol. 139, no. 4, pp. 423-433, 2013.

[16] C. M. Eastman, BIM Handbook: A Guide to Building Information Modeling for Owners, Managers, Designers, Engineers and Contractors, Wiley, 2008.

[17] S. Abourizk, "Role of simulation in construction engineering and management," Journal of Construction Engineering and Management, vol. 136, no. 10, pp. 1140-1153, 2010.
[18] K. Barlish and K. Sullivan, "How to measure the benefits of BIM-a case study approach," Automation in Construction, vol. 24, pp. 149-159, 2012.

[19] S. Staub-French and A. Khanzode, “3D and 4D modeling for design and construction coordination: issues and lessons learned," Electronic Journal of Information Technology in Construction, vol. 12, pp. 381-407, 2007.

[20] F. M. Arain and M. Burkle, "Learning construction project management in the virtual world: leveraging on second life," Electronic Journal of Information Technology in Construction, vol. 16, pp. 243-258, 2011.

[21] I.-C. Wu and S.-H. Hsieh, "A framework for facilitating multidimensional information integration, management and visualization in engineering projects," Automation in Construction, vol. 23, pp. 71-86, 2012.

[22] C.-W. Feng, Y.-J. Chen, and J.-R. Huang, "Using the MD CAD model to develop the time-cost integrated schedule for construction projects," Automation in Construction, vol. 19, no. 3, pp. 347-356, 2010.

[23] D. C. Kent and B. Becerik-Gerber, "Understanding construction industry experience and attitudes toward integrated project delivery," Journal of Construction Engineering and Management, vol. 136, no. 8, pp. 815-825, 2010. 

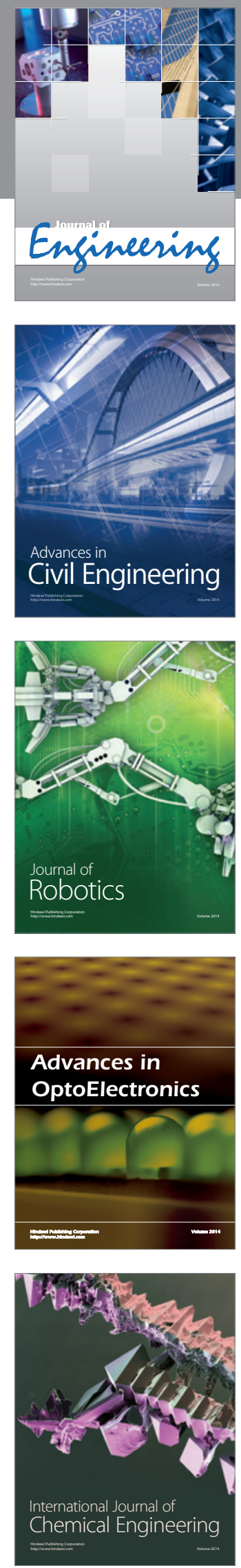

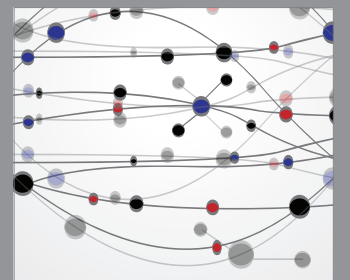

The Scientific World Journal
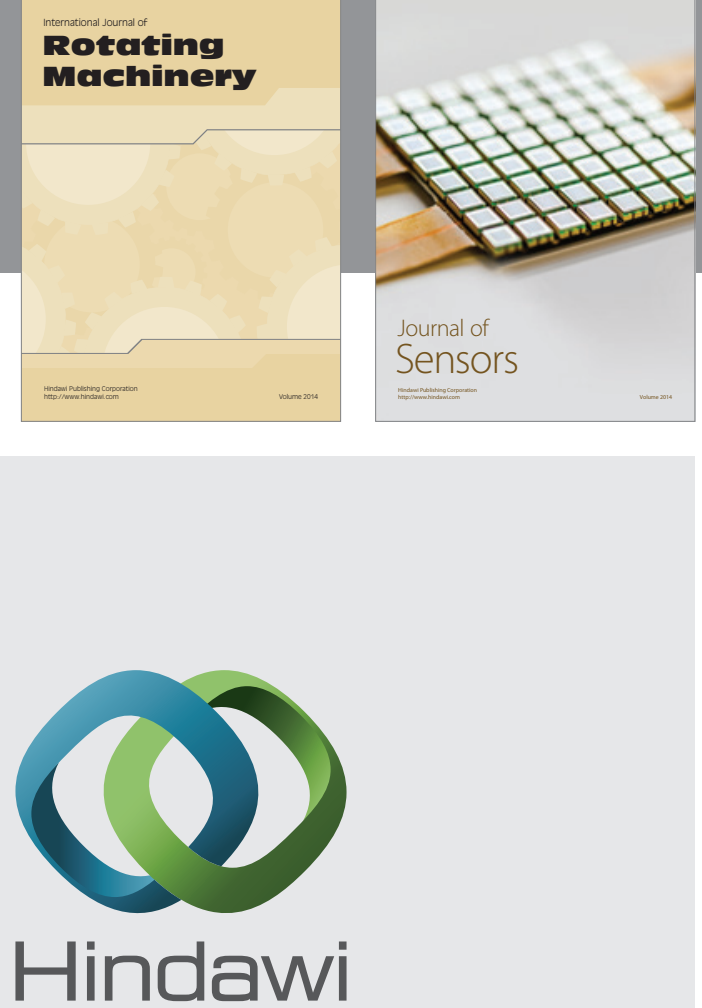

Submit your manuscripts at http://www.hindawi.com
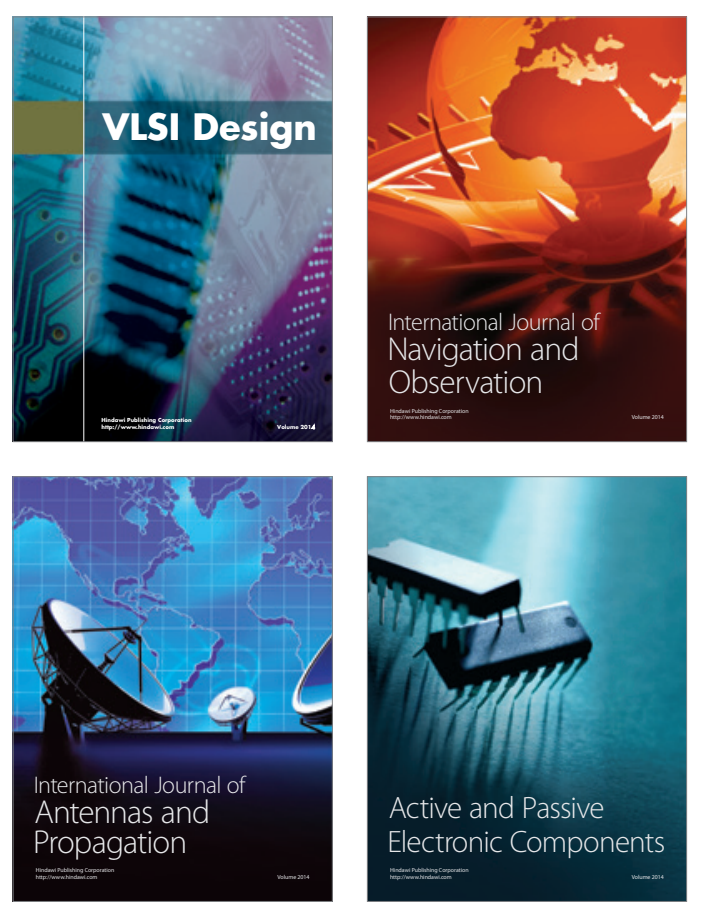
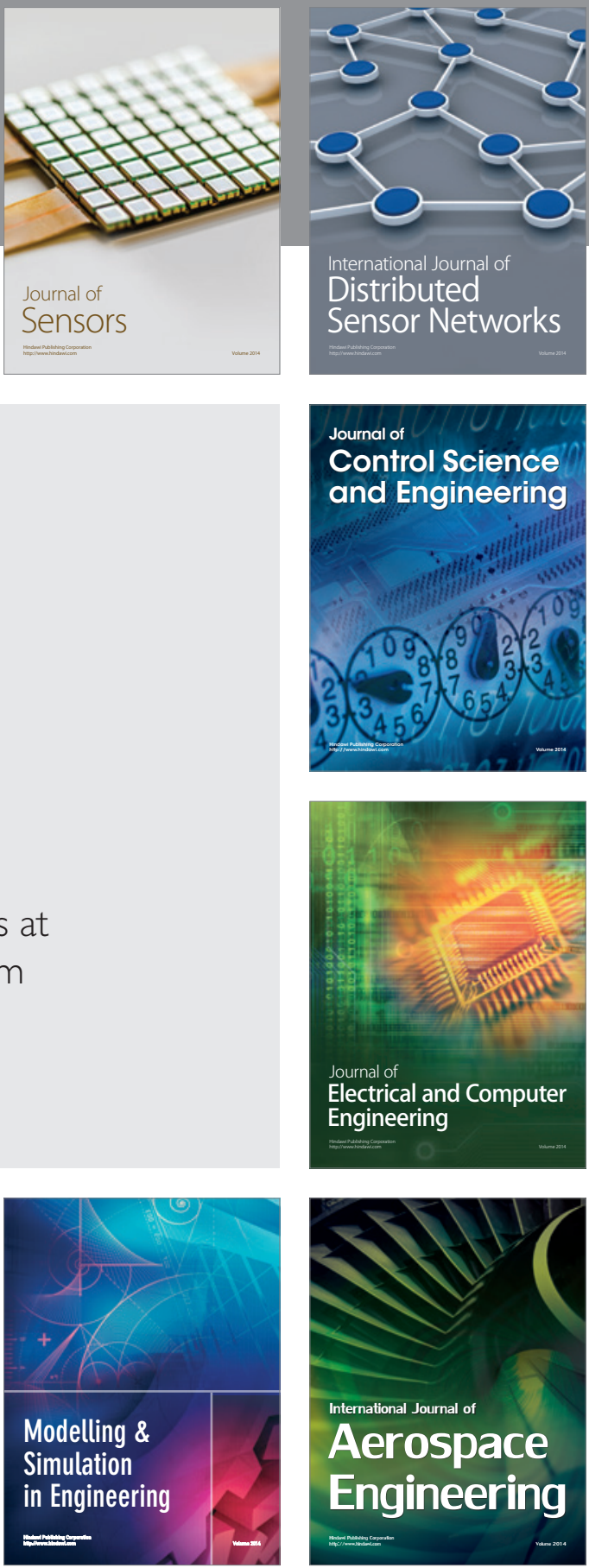

Journal of

Control Science

and Engineering
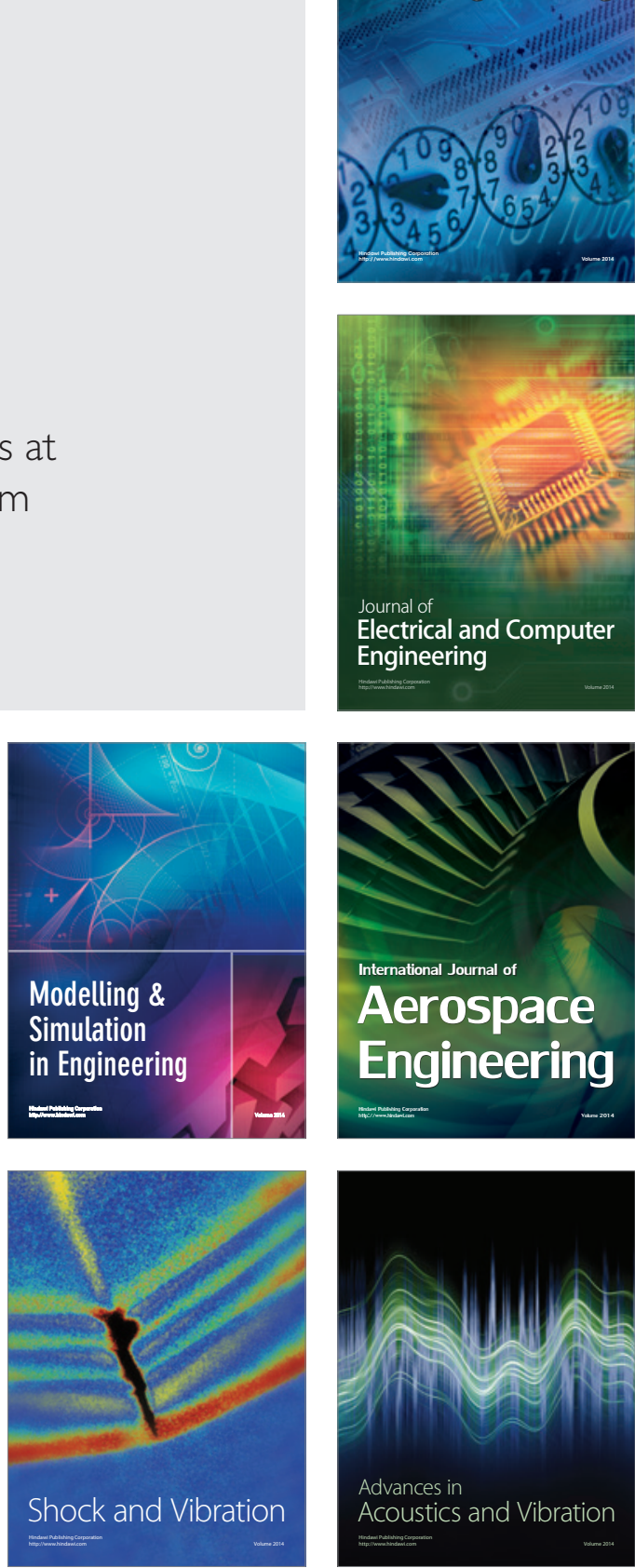